University of Wollongong

Research Online

Australian Institute for Innovative Materials -

Papers

Australian Institute for Innovative Materials

$1-1-2019$

\title{
Morphology tuning of inorganic nanomaterials grown by precipitation through control of electrolytic dissociation and supersaturation
}

\author{
Weihong Lai \\ University of Wollongong,weihongl@uow.edu.au \\ Yunxiao Wang \\ University of Wollongong, yunxiao@uow.edu.au \\ Yong Wang \\ Shanghai University \\ Minghong Wu \\ Shanghai University \\ Jiazhao Wang \\ University of Wollongong, jiazhao@uow.edu.au
}

See next page for additional authors

Follow this and additional works at: https://ro.uow.edu.au/aiimpapers

Part of the Engineering Commons, and the Physical Sciences and Mathematics Commons

Research Online is the open access institutional repository for the University of Wollongong. For further information contact the UOW Library: research-pubs@uow.edu.au 


\title{
Morphology tuning of inorganic nanomaterials grown by precipitation through control of electrolytic dissociation and supersaturation
}

\author{
Abstract \\ The precise control of the morphology of inorganic materials during their synthesis is important yet \\ challenging. Here we report that the morphology of a wide range of inorganic materials, grown by rapid \\ precipitation from a metal cation solution, can be tuned during their crystallization from one- to three- \\ dimensional (1D to 3D) structures without the need for capping agents or templates. This control is \\ achieved by adjusting the balance between the electrolytic dissociation $(\alpha)$ of the reactants and the \\ supersaturation (S) of the solutions. Low- $\alpha$, weak electrolytes promoted the growth of anisotropic (1D \\ and 2D) samples, with 1D materials favoured in particular at low S. In contrast, isotropic 3D polyhedral \\ structures could only be prepared in the presence of strong electrolyte reactants $(\alpha \approx 1)$ with low $S$. Using \\ this strategy, a wide range of materials were prepared, including metal oxides, hydroxides, carbonates, \\ molybdates, oxalates, phosphates, fluorides and iodate with a variety of morphologies.

\section{Disciplines} \\ Engineering | Physical Sciences and Mathematics

\section{Publication Details} \\ Lai, W., Wang, Y., Wang, Y., Wu, M., Wang, J., Liu, H., Chou, S., Chen, J. \& Dou, S. (2019). Morphology tuning \\ of inorganic nanomaterials grown by precipitation through control of electrolytic dissociation and \\ supersaturation. Nature Chemistry, 11 (8), 695-701.

\section{Authors} \\ Weihong Lai, Yunxiao Wang, Yong Wang, Minghong Wu, Jiazhao Wang, Hua-Kun Liu, Shulei Chou, Jun \\ Chen, and Shi Xue Dou
}




\title{
Morphology tuning of inorganic nanomaterials grown by precipitation through control of electrolytic dissociation and supersaturation
}

\author{
Wei-Hong Lai, ${ }^{\dagger 1}$ Yun-Xiao Wang, ${ }^{\dagger 1}$ Yong Wang ${ }^{\S}$, Minghong Wu ${ }^{\S, *}$, Jia-Zhao Wang, ${ }^{\dagger, *}$ Hua- \\ Kun Liu ${ }^{\dagger}$, Shu-Lei Chou ${ }^{\dagger, *}{ }^{*}$ Jun Chen ${ }^{\uparrow, *}$ and Shi-Xue Dou ${ }^{\dagger}$
}

${ }^{\dagger}$ Institute for Superconducting \& Electronic Materials, Innovation Campus, University of Wollongong, Wollongong, NSW 2500, Australia.

*Correspondence author email: shulei@uow.edu.au; jiazhao@uow.edu.au

§Shanghai Applied Radiation Institute, Faculty of Environmental and Chemical Engineering, Shanghai University, 99 Shangda Road, Shanghai 200444.

*Corresponding author email: mhwu@staff.shu.edu.cn

"Key Laboratory of Advanced Energy Materials Chemistry (Ministry of Education), College of Chemistry, Nankai University, Tianjin 300071, P. R. China.

*Corresponding author email: chenabc@nankai.edu.cn

\section{Abstract}

The precise control of the morphology of inorganic materials during their synthesis is important yet challenging. Here, we report that the morphology of a wide range of inorganic materials, grown by rapid precipitation from a metal cation solution, can be tuned during their crystallization from one- to three-dimensional (1D-3D) structures, without the need for capping agent or templates. This control is achieved by adjusting the balance between the electrolytic dissociation ( $\alpha$ ) of reactants and the supersaturation $(S)$ of solutions. Low- $\alpha$ weak electrolytes promoted the growth of anisotropic (1D and 2D) samples, with 1D materials favoured in particular at low $S$. In contrast, isotropic 3D polyhedral structures could only be prepared in the presence of strong electrolyte reactants $(\alpha \approx 1)$ with low $S$. Using this strategy, a wide range of materials were prepared, including metal oxides, hydroxides, carbonates, molybdates, oxalates, phosphates, fluorides, and iodate with a variety of morphologies.

Materials with well-defined microscopic and nanoscopic morphologies hold great promise for various practical applications, for example in catalysis, batteries, semiconductors, supercapacitors, 
hydrogen storage, and magnetic and optical devices ${ }^{1-5}$. These can be tuned to some extent by traditional synthesis methods, such as the hydro- or solvothermal method, preformed-seedmediated growth strategy, polyol approach, template method, and electrochemical synthesis, but those are not ideal for large-scale commercialization because they typically require complex equipment, the use of toxic solvents, and time-consuming high-temperature or high-pressure processes $^{6-10}$.

A variety of inorganic materials can also be obtained through a straightforward precipitation process. This growth method is widely used and generally well-understood ${ }^{11-12}$, but the rapid reaction rates involved make it difficult to precisely control the morphologies of the resulting products. We carried out a systematic study to explore precipitation processes carried out in a variety of electrolytes with different degrees of dissociation, to better understand the chemical driving force of the precipitation process and in turn precisely regulate the concentration of the reactants in solution to promote the precipitation of the desired species. Tuning two factors, the supersaturation $(S)$ of solutions and the electrolytic dissociation $(\alpha)$ of reactants, enabled the control of morphologies from 1D to 3D during the rapid, room-temperature crystal growth.

$S$ is widely known to significantly influence the surface engineering of crystals ${ }^{13}$. Theoretically, for each specialized material, the concentration of the desired ions in the solution determines the $S$ by the following equation:

$$
S=\sqrt[2]{\frac{C_{M} \times\left(C_{D A}\right)^{\delta}}{k_{S p}}}
$$

where $C_{M}$ and $C_{D A}$ represent the concentration of metal cations and dissociated reactant anions, respectively, $\delta$ is the number of ions in the material's formula unit, and $\mathrm{K}_{\mathrm{sp}}$ is the solubility product constant ${ }^{14-15}$. This means that regulating the concentration of ions is crucial in thermodynamic growth $^{16}$. Meanwhile, it is believed that both thermodynamic and kinetic effects influence the processes of precipitation through steps such as pre-nucleation, nucleation, and growth ${ }^{17-19}$. Organic surfactants have been commonly used to obtain kinetic control over orientated nanocrystal growth by selective adhesion effects along the organic-inorganic interface ${ }^{20}$. Nevertheless, without the aid of capping agents and templates, controlling the evolution of crystallization by precipitation is not well understood and extremely challenging. 
Here, we show that the judicious choice of reactants enables the successful synthesis of a series of precipitates with elaborate morphologies. We describe in particular the growth of various materials with adjustable morphologies through a rapid room-temperature precipitation process, including 1D metal hydroxides $\left(\mathrm{M}(\mathrm{OH})_{2}, \mathrm{M}=(\mathrm{Co}, \mathrm{Mg}, \mathrm{Mn}, \mathrm{Zn})\right), \mathrm{Cu}_{2}(\mathrm{OH})_{2} \mathrm{SO}_{4}$, metal carbonates $\left(\mathrm{MCO}_{3}, \mathrm{M}=(\mathrm{Co}, \mathrm{Ba}, \mathrm{Sr})\right), \mathrm{BaF}_{2}, \mathrm{CoC}_{2} \mathrm{O}_{4}$ and $\mathrm{BaMoO}_{4} ; 2 \mathrm{D}$ metal hydroxides $\left(\mathrm{M}(\mathrm{OH})_{2}, \mathrm{M}=(\mathrm{Co}\right.$, $\mathrm{Ni}, \mathrm{Mg}, \mathrm{Mn}, \mathrm{Zn}), \mathrm{Cu}_{2}(\mathrm{OH})_{2} \mathrm{SO}_{4}, \mathrm{Co}_{2} \mathrm{~S}(\mathrm{OH})_{2}, \mathrm{Ca}_{3}\left(\mathrm{PO}_{4}\right)_{2}, \mathrm{Cu}_{2}\left(\mathrm{Fe}(\mathrm{CN})_{6}\right), \mathrm{CoCO}_{3}, \mathrm{BaMoO}_{4}$, $\mathrm{Ca}(\mathrm{OH})_{2}$, and $\mathrm{BaF}_{2}$; and 3D metal hydroxides $\left(\mathrm{M}(\mathrm{OH})_{2}, \mathrm{M}=(\mathrm{Cu}, \mathrm{Co}, \mathrm{Mn}, \mathrm{Mg}, \mathrm{Ca})\right), \mathrm{CaCO}_{3}$, $\mathrm{BaF}_{2}, \mathrm{CuC}_{2} \mathrm{O}_{4}, \mathrm{BaMoO}_{4}$, and $\mathrm{Ca}\left(\mathrm{IO}_{3}\right)_{2}$. Based on our study of a variety of conditions, we propose that the use of strong electrolytes ( $\alpha \approx 1)$, such as $\mathrm{NaOH}, \mathrm{NaF}$, and $\mathrm{Na}_{2} \mathrm{MoO}_{4}$, is imperative to achieve isotropic growth and produce various 3D precipitates. In contrast, when the precipitation was carried out using weak electrolytes $(\alpha \ll 1)$, such as $\mathrm{NH}_{4} \mathrm{OH}, \mathrm{NH}_{4} \mathrm{HF}_{2}$, and $\mathrm{CO}\left(\mathrm{NH}_{2}\right)_{2}$, the process could be tuned to form either 1D rod-like or 2D nanosheet structures. In this case, lower $S$ favors the formation of 1D nanostructures, whereas higher $S$ typically promoted 2D morphologies.

\section{Results and discussion}

\section{Synthesis of tunable inorganic materials}

In a typical synthesis, an aqueous solution containing metal cations (such as $\mathrm{Co}\left(\mathrm{NO}_{3}\right)_{2} \cdot 6 \mathrm{H}_{2} \mathrm{O}$ ) was first prepared. Another solution of an appropriate precipitant (such as $\mathrm{NH}_{4} \mathrm{OH}$ ) was then added at room temperature, under stirring at the rate of $300 \mathrm{rpm}$. The desired precipitation products (such as in this case $\mathrm{Co}(\mathrm{OH})_{2}$ nanosheets) were immediately obtained. Reactants with different $\alpha$ were used; the dissociation equilibrium is shown in Equation (2),

$$
\alpha=C_{D A} / C_{R}
$$

where $C_{D A}$ and $C_{R}$ represent the concentration of dissociated anions and the concentration of reactant, respectively.

Typically, a strong electrolyte $(\alpha \approx 1)$ could instantly release sufficient ions and lead to fast nucleation and a high growth rate for precipitation. For a weak electrolyte $(\alpha \ll 1)$, the gradual release of target ions is expected to slow down the kinetics of nucleation and growth ${ }^{21}$. Thus, reactants with different $\alpha$ values can precisely regulate the concentration of desired ions and simultaneously manage to achieve appropriate $S$, which plays a critical role in obtaining various 
products according to their solubility product constant $\left(\mathrm{K}_{\mathrm{sp}}\right)$. Additionally, it is well known that the size of crystallites decreases with increasing $S$, which is mainly governed by the nucleation process.

For materials with high $\mathrm{K}_{\mathrm{sp}}$, precipitation occurs in a solution with low saturation, which indicates that $3 \mathrm{D}$ isotropic growth is very favorable. In the case of $\mathrm{BaF}_{2}$, when a strong electrolyte $\mathrm{NaF} / \mathrm{F}^{-}$(reactant/dissociated anions) ( $\left.\alpha \approx 1\right)$ was used as precipitant, a supersaturated solution with $S=70$ rapidly formed, which results in the formation of 3D polyhedra (Fig. 1aI). In contrast, the evolution of $\mathrm{BaF}_{2}$ from isotropic to anisotropic, achieved by using $\mathrm{NH}_{4} \mathrm{HF}_{2}$ instead of $\mathrm{NaF}$, indicates that the presence of the weak electrolyte is another factor (besides the control of supersaturation) that can provide a kinetic driving force to support an anisotropic growth as well. The use of weak electrolyte $\mathrm{NH}_{4} \mathrm{HF}_{2} / \mathrm{F}^{-}(\alpha=0.165)$ leads to the formation of $1 \mathrm{D}$ rod-like structures from a solution with $S=12.4$ and 2D nanoplate structures through a quick anisotropic growth process in a solution of $S=40(\alpha=0.32)$ (Fig. $1 \mathrm{aII}$ and III). It is notable that $\mathrm{BaF}_{2}$ could further transform from 1D to 2D (Supplementary Table 1) on increasing the supersaturation $S$ by using weak electrolytes with a relative high $\alpha$. The manipulation from $3 \mathrm{D}$ to $1 \mathrm{D}$ for high- $\mathrm{K}_{\mathrm{sp}}$ materials is simple, because it is relatively easy to tune a slightly supersaturated environment (Fig. 1a).

On the other hand, for low- $\mathrm{K}_{\mathrm{sp}}$ materials such as metal hydroxides $\left(\mathrm{Co}(\mathrm{OH})_{2}, \mathrm{MnOOH}\right)$ (Supplementary Table 1), the solution is saturated so quickly that a high number of nuclei of the precipitates are generated. The solution with a high supersaturation causes a high chemical potential, which is converted as surface energy of crystallites via the Thomson-Gibbs equation. ${ }^{13}$ The high surface energy is responsible for the extremely high nucleation rate during a short-time crystallization, leading to the formation of small, irregular particles, where the morphology is hard to control. In particular, when strong electrolytic $\mathrm{NaOH}$ was selected as reactant, the corresponding metal hydroxides solution had extremely high $S\left(S_{\mathrm{Co}(\mathrm{OH}) 2}=222,887\right)$, leading to the formation of aggregated small irregular particles (Supplementary Fig. 1). In order to form 3D regular nanostructures, the solution should therefore exhibit low supersaturation to decrease the reaction rate on nucleation and thus achieve isotropic crystal growth into regular shape. An effective technique to resolve this problem is to decrease the concentration of metal cations, for example by using $\mathrm{CoCO}_{3}, \mathrm{MgF}_{2}, \mathrm{MnCO}_{3}$, and $\mathrm{CuC}_{2} \mathrm{O}_{4}$ as metal ion sources instead of $\mathrm{Co}\left(\mathrm{NO}_{3}\right)_{2}, \mathrm{Mg}\left(\mathrm{NO}_{3}\right)_{2}$, $\mathrm{MnSO}_{4}$, and $\mathrm{CuSO}_{4}$, respectively. This is because these salts $\left(\mathrm{CoCO}_{3}, \mathrm{MgF}_{2}, \mathrm{MnCO}_{3}\right.$, and $\mathrm{CuC}_{2} \mathrm{O}_{4}$ ) are only slightly soluble, so that they can only provide very limited concentrations of 
metal ions, leading to relatively low supersaturation and the formation of 3D polyhedra. As shown in Fig. 1(b-f)I, 3D polyhedral products $\left(\mathrm{BaMoO}_{4}, \mathrm{Mg}(\mathrm{OH})_{2}, \mathrm{Co}(\mathrm{OH})_{2}, \mathrm{MnOOH}, \mathrm{Cu}(\mathrm{OH})_{2}\right)$ are successfully obtained. Similarly, suitable weak electrolytes can be used to produce 1D and 2D nanostructures for those low-K $\mathrm{K}_{\mathrm{sp}}$ samples. Lower supersaturation results in the formation of 1D $\mathrm{BaMoO}_{4}, \mathrm{Mg}(\mathrm{OH})_{2}, \mathrm{Co}(\mathrm{OH})_{2}, \mathrm{MnOOH}$, and $\mathrm{Cu}_{2}(\mathrm{OH})_{2} \mathrm{SO}_{4}$, respectively (Fig. 1(b-f)II). Higher supersaturation is responsible for the corresponding 2D morphology (Fig. 1(b-f)III). For example, urea with low- $\alpha\left(\alpha=2.25 \times 10^{-6}\right)$ leads to the growth of $1 \mathrm{D} \mathrm{Cu}_{2}(\mathrm{OH})_{2} \mathrm{SO}_{4}$ (Fig. 1fII), and in turn, $\mathrm{NH}_{4} \mathrm{OH}$ with relatively high $\alpha\left(\alpha=2.68 \times 10^{-2}\right)$ facilitates the formation of nanosheets of $\mathrm{Cu}_{2}(\mathrm{OH})_{2} \mathrm{SO}_{4}$ (Fig. 1fIII).

These results indicate that the $\alpha$ of reactants and $S$ of solutions play key roles in shape control. Specifically, only a strong electrolyte could lead to the formation of 3D anisotropic growth. In contrast, the weak electrolytes are favorable to achieve 1D or 2D isotropic growth, in which the evolution from 1D to 2D could be controlled by increasing $S$, which, in turn, is determined by selecting relatively high- $\alpha$ electrolytes. The values for $\alpha$ and $S$ induced materials, including $\mathrm{BaF}_{2}$, $\mathrm{BaMoO}_{4}, \mathrm{Mg}(\mathrm{OH})_{2}, \mathrm{Co}(\mathrm{OH})_{2}, \mathrm{MnOOH}$, and $\mathrm{Cu}_{2}(\mathrm{OH})_{2} \mathrm{SO}_{4}$, are summarized in Fig. 1(a-f)IV. For example, the value of $\log _{10}(\alpha)$ of $3 \mathrm{D}-\mathrm{BaF}_{2}$ tends to 0 , which means that $\alpha \approx 1$, indicating that the strong electrolyte can release its $\mathrm{F}^{-}$anions quickly, while $1 \mathrm{D}$ and $2 \mathrm{D} \mathrm{BaF}_{2}$ have much lower $\log _{10}(\alpha)$ values. This is the most common principle of evolution from anisotropic to isotropic structures, that is, strong electrolytes tend to promote the formation of 3D samples, while the weak electrolytes can be used for the synthesis of isotropic materials. This pattern can also be seen in these other materials, including $\mathrm{BaMoO}_{4}, \mathrm{Mg}(\mathrm{OH})_{2}, \mathrm{Co}(\mathrm{OH})_{2}, \mathrm{MnOOH}$, and $\mathrm{Cu}_{2}(\mathrm{OH})_{2} \mathrm{SO}_{4}$. Moreover, we observe that increasing $S$ promoted a change of morphology from 1D to 2D for all materials.

To further explore the generality of this issue, more $1 \mathrm{D}$ samples, including $\mathrm{BaCO}_{3}, \mathrm{CoCO}_{3}$, $\mathrm{CoC}_{2} \mathrm{O}_{4}, \mathrm{Zn}(\mathrm{OH})_{2}$, and $\mathrm{SrCO}_{3}$ (Fig. 2a-d, Supplementary Fig. 2), were successfully prepared by using various complexes with low $\alpha$, such as $\mathrm{CO}_{2} / \mathrm{CO}_{3}{ }^{2-}$ (considering that $\mathrm{CO}_{2}$ gas can continuously provide soluble $\mathrm{CO}_{3}{ }^{2-}$, which is similar to a weak electrolyte), $\mathrm{NaHC}_{2} \mathrm{O}_{4} / \mathrm{C}_{2} \mathrm{O}_{4}{ }^{2-}$, and $\mathrm{Na}_{2} \mathrm{SO}_{4} / \mathrm{OH}^{-}$. Also, 2D nanosheets, such as from metal hydroxides $\left(\mathrm{M}(\mathrm{OH})_{2}, \mathrm{M}=\mathrm{Ni}\right.$, Zn, metal sulfide hydroxides $\left(\mathrm{Co}_{2} \mathrm{~S}(\mathrm{OH})_{2}\right)$, and metal phosphate $\left(\mathrm{Ca}_{3}\left(\mathrm{PO}_{4}\right)_{2}\right)$, were synthesized in high $S$ by using $\mathrm{NH}_{4} \mathrm{OH} / \mathrm{OH}^{-}, \mathrm{CH}_{3} \mathrm{COONa} / \mathrm{OH}^{-}$, and $\mathrm{Na}_{2} \mathrm{HPO}_{4} / \mathrm{PO}^{3-}$ (Fig. 3e-h). The TEM images of representative 2D materials show rolled-up edges and wrinkled structures, indicating ultrathin 
materials ${ }^{8}$. The thickness of typical materials, such as $\mathrm{Ni}(\mathrm{OH})_{2}$ and $\mathrm{MnOOH}$, is only 10-14 $\AA$, corresponding to approximately four-atomic layers, as shown by both HRTEM and atomic force microscopy (AFM) images (Supplementary Fig. 3). These 2D crystals with atomic thickness show enhanced intrinsic properties and expanded utilization beyond what is possible with the bulk materials ${ }^{22}$.

Furthermore, the low-magnification scanning electron microscope (SEM) images of various low-dimensional materials confirm that this facile approach could achieve high quality and excellent uniformity of anisotropic products (Supplementary Figs. 4 and 5). The elemental mapping analysis of representative 1D and 2D samples demonstrates that the expected elements are uniformly distributed within their corresponding morphologies (Supplementary Figs. 6 and 7). More specifically, the $1 \mathrm{D}$ materials formed in a solution with low $S$ are found to grow into single crystalline form with a dominant direction, but polycrystalline samples are formed for 2D materials obtained in a high-S solution (Supplementary Fig. 8); thus, the electronic structure of precipitates could be tuned to realize variable crystalline structures and band gaps via selecting $\alpha$ in relation to $S$ (Supplementary Figs. 9-11). Meanwhile, the X-ray diffraction patterns of these 1D, 2D, and 3D materials can be indexed to their corresponding crystalline phases (Supplementary Figs. 12-14), confirming the formation of diverse products. Similarly, with strong electrolytes, such as $\mathrm{NaOH} / \mathrm{OH}^{-}, \mathrm{Na}_{2} \mathrm{MoO}_{4} / \mathrm{MoO}_{4}{ }^{2-}$, and $\mathrm{Na}_{2} \mathrm{CO}_{3} / \mathrm{CO}_{3}{ }^{2-}$, the resultant precipitates are prone to exhibit $3 \mathrm{D}$ isotropic polyhedral morphology, including $\mathrm{Ca}(\mathrm{OH})_{2}, \mathrm{CaCO}_{3}, \mathrm{CuC}_{2} \mathrm{O}_{4}$, and $\mathrm{Ca}\left(\mathrm{IO}_{3}\right)_{2}$ (Fig.3il) in a slightly saturated solution. These 3D materials show different polyhedral morphologies, such as spheres, cuboctahedra, cubes, octahedra, and dodecahedra.

\section{Balance between electrolytic dissociation and supersaturation}

To further investigate the mechanism, the calculated values of $\log _{10}(S), \log _{10}(\alpha)$, and $-\log _{10}\left(\mathrm{~K}_{\mathrm{sp}}\right)$ applied in selected materials with different dimensions are summarized in Fig. 3a (Supplementary Table 1). From the projected image of $\log _{10}(S)$ vs. $-\log _{10}\left(K_{\mathrm{sp}}\right)$, the supersaturation $S$ of $1 \mathrm{D}$ materials is separated from that of the 2D materials by the critical threshold of supersaturation. Compared to $2 \mathrm{D}$ materials, the $1 \mathrm{D}$ materials are prone to grow in a solution at lower supersaturation, which is achieved upon the synchronous with low $\alpha$, such $\mathrm{K}_{\mathrm{sp}}$ (Fig. 4b). Also, according to the projected image of $\log _{10}(\alpha)$ vs. $-\log _{10}\left(K_{\mathrm{sp}}\right)($ Fig. 3c), isotropic (3D) structured materials are located at the top 
near to the $\log _{10}(\alpha)$ value 0 , but anisotropic (1D and 2D) structured samples have relatively low $\log _{10}(\alpha)$, which indicates that low $\alpha$ determines the anisotropic growth. Moreover, as summarized in Fig. 3d and Supplementary Fig. 15, the $S$ tuned by $\alpha$ is the most critical factor to determine the specific 3D morphology, in which $S_{\text {irregular particles }}>S_{\text {spheres }}>S_{\text {polyhedra; }}$ for instance, $\mathrm{CaCO}_{3}$ polyhedra (Fig. 2j) could be tuned into spheres by increasing $S$ from 56 to 154 (Supplementary Fig. 15). More specifically, the evolution amongst multiple dimensions has been simulated in Supplementary Fig. $16 \mathrm{a}$ and $\mathrm{b}$, which indicates the morphologies distribution of various materials (different $\mathrm{K}_{\mathrm{sp}}$ ) with $1-3 \mathrm{D}$ edges tuned by $S$ and $\alpha$, respectively. This process can be confirmed by preparing the mixture of $2 \mathrm{D}$ and $1 \mathrm{D} \mathrm{Cu}_{2}(\mathrm{OH})_{2} \mathrm{SO}_{4}$ through using relatively high- $\alpha$ aniline to replace urea (Supplementary Fig. 16 and Fig. 1fII).

\section{Formation mechanisms}

The formation processes of various morphologies are illustrated in Fig. 4a. For the weak electrolytes, once the precipitation reaction between reactant anions and metal cations occurs, the non-equilibrium environment of a weak electrolyte serves as a chemical driving force to trigger the release of new anions from the reactant and induce the outward-migration for continuous growth of precipitation. Also, the cycle of achieving re-equilibrium of a weak electrolyte based on $\alpha$ can provide a consistent kinetic driving force to support the orientated expansion of growth. Specifically, when a low- $S$ solution is achieved, the material is favorable to be a slow epitaxial

growth, leading to 1D morphology (The green reacting path). When a weak electrolyte is relatively strong and can release more anions during dissociation process, a high- $S$ solution can be realized with a larger saturated region, which can support 2D growth rather than $1 \mathrm{D}$ growth. (The orange reacting path). In contrast, strong electrolyte-based reactants with $\alpha \approx 1$ can completely release the precipitant anions all at once, which results in the absence of a chemical driving force formed within the period of growth, so that the materials uniformly grow on each axis and are prone to form 3D isotropic morphologies. In particular, when the solution is controlled with a low $S$, the precipitates can have regular shapes with relatively slow growth rate rather than irregular small particles if in high-S condition. Thus, when selecting different weak electrolytes as anion-releasing solutions, the reaction solutions can be regulated to achieve different degrees of $S$, leading to 1Dcrystal growth for a low-S solution and 2D structure in a high- $S$ solution, respectively. By contrast, 
the strong electrolytes enable the formation of 3D regular crystals in a low-S solution. This approach was successfully extended to the synthesis of different complexes with anisotropic structure, including $1 \mathrm{D} \mathrm{Cu}(\mathrm{OH})_{2}$ and 2D $\mathrm{Cu}_{2}\left(\mathrm{Fe}(\mathrm{CN})_{6}\right)$ (Supplementary Figs. 17-19). This precipitation strategy, based on adjusting $S$ relatively to $a$, represents a universal way to tune $1 \mathrm{D}$, 2D, and 3D morphologies for a wide range of materials.

More importantly, this approach is a flexible way to explore diverse unique nanostructures by virtue of various auxiliary conditions. The growth of $\mathrm{Ca}(\mathrm{OH})_{2}$ materials can be tuned to form either polyhedra (Fig. 2i) or nanoflakes by changing the sequence in which reactants are added. When adding $\mathrm{Ca}\left(\mathrm{CH}_{3} \mathrm{COO}\right)_{2}$ into $\mathrm{NaOH}$, the dissociation equilibrium of $\mathrm{Ca}\left(\mathrm{CH}_{3} \mathrm{COO}\right)_{2}$ can be interrupted by $\mathrm{OH}^{-}$and work as a weak electrolyte, continuously releasing $\mathrm{Ca}^{2+}$ as a kinetic driving force. Meanwhile, the mixed solution shows high $S$, generated very quickly at the interface of the growing material by the high concentration of $\mathrm{OH}^{-}$. Like the reaction mechanism illustrated in Fig. 4b, the two factors jointly lead to favorable 2D growth into nanoflakes. (Supplementary Fig. 20).

We found that the mechanical driving force also influences the growth of the materials. For example, by increasing the stirring rate, the morphology of $\mathrm{Co}(\mathrm{OH})_{2}$ with $\mathrm{NaOH}$ as precipitant changes from aggregated irregular particles into small nanoplates, and $\mathrm{CaCO}_{3}$ evolves from large layer-stacked secondary particles to small layer-stacked secondary particles (Supplementary Fig. 21). The increased stirring speed facilitates the reaction between metal cations and reactant anions, leading to increased $S$ and abundant nucleation, which is conducive to structural evolution and smaller size. Furthermore, we found that the $\mathrm{pH}$ values due to reactant dissociation, or even deliberate $\mathrm{pH}$ adjustment, mostly induce slight structural variations, such as crystalline structures and nanosize, but the presupposed morphologies are maintained, especially for anisotropic materials (Supplementary Fig. 22). This innovative and facile technique is simply modified and realized several distinctive nanostructures for the first time with high specific surface areas, including hollow $\mathrm{BaF}_{2}$ tubes and cubes, porous $\mathrm{CaF}_{2}$ cubes, and holey $\mathrm{Co}(\mathrm{OH})_{2}$ sheets (Fig. 4b-e, Supplementary Figs. 23-26). These structures can hugely increase the specific surface area, which is in turn likely to increase performance in potential applications.

The precipitates obtained represent a wide variety of common materials, which generally hold promise for a broad scope of applications, such as in energy storage and conversion. As shown in Supplementary Fig. 27, 1D Co(OH) 2 has an overpotential $\left(\eta_{1 \mathrm{D}}\right)$ of $310 \mathrm{mV}$, which indicates better 
oxygen evolution reaction (OER) performance than $2 \mathrm{D}$ and $3 \mathrm{D} \mathrm{Co}(\mathrm{OH})_{2}\left(\eta_{2 \mathrm{D}}=400 \mathrm{mV}\right.$ and $\eta_{3 \mathrm{D}}$ $=400 \mathrm{mV}$ ). $\mathrm{BaF}_{2}$ shows decent performance for the oxygen reduction reaction (ORR). Compared with $1 \mathrm{D}$ and $3 \mathrm{D} \mathrm{BaF}_{2}$, the as-prepared $2 \mathrm{D} \mathrm{BaF}_{2}$ shows the highest half-potential $E_{1 / 2}$, suggesting its superior efficiency towards oxygen reduction. 2D $\mathrm{Co}(\mathrm{OH})_{2}$-derived $\mathrm{CoO}$ mesoporous nanosheets exhibit good electrochemical performance when applied as an anode in lithium-ion batteries (LIBs), delivering high reversible capacity ( $\left.\sim 850 \mathrm{mAh} \mathrm{g}^{-1}\right)$ at a current density of $2 \mathrm{~A} \mathrm{~g}^{-}$ ${ }^{1}$ after 400 cycles, and the high rate capability of $\sim 700 \mathrm{~mA} \mathrm{~h} \mathrm{~g}^{-1}$ at a current density of $5 \mathrm{~A} \mathrm{~g}^{-1}$ (Supplementary Fig. 28). The better performances of 2D $\mathrm{Co}(\mathrm{OH})_{2}$-derived $\mathrm{CoO}$ mesoporous nanosheets compared with the reported results on various $\mathrm{CoO}$ anodes (including nanocages ${ }^{23}$, porous nanowire arrays ${ }^{24}$, multilayer platelets ${ }^{25}$, microspheres ${ }^{26}$, mesoporous nanorods ${ }^{27}$, mesoporous nanodiscs ${ }^{28}$, microsheets $^{29}$, and nanowire clusters ${ }^{30}$ ) stems from their nanoarchitecture . (Supplementary Figs. 29-31). Furthermore, the $\mathrm{CoO}$ nanosheets retained their mesoporous structure after 400 cycles (Supplementary Fig. 32). To illustrate the commercial potential of $\mathrm{CoO}$ mesoporous nanosheets, mass produced from the $2 \mathrm{D} \mathrm{Co}(\mathrm{OH})_{2}$ nanosheets and obtained here in high yield, we assembled a pouch-type full cell by pairing with a $\mathrm{LiFePO}_{4}$ cathode (Supplementary Figs. 33 and 34).

In summary, we successfully fabricated a wide variety of materials by virtue of our rapid chemical precipitation strategy. Reactants as precipitants with different $\alpha$ values can precisely regulate the concentration of desired ions and simultaneously manage to achieve appropriate $S$, which plays a critical role in obtaining various products according to their solubility product constant $\left(\mathrm{K}_{\mathrm{sp}}\right)$. The synergetic control between $\alpha$ of reactants and $S$ of precipitates, therefore, can tune the morphology from 1D to 3D through quick precipitation. The formation of $1 \mathrm{D}$ and 2D materials relies on the low dissociation capability of weak electrolytes. The selection of a strong electrolyte $(\alpha \approx 1)$ is conducive to the growth of isotropic 3D structures. Moreover, lower supersaturation is critical for the formation of $1 \mathrm{D}$ and $3 \mathrm{D}$ polyhedral structures, whereas 2D materials require a high supersaturation condition. We hope that these insights will help the facile synthesis, and morphology control, of a variety of materials.

\section{References}

1. Guo, Y. G.; Hu, J. S.; Wan, L. J., Nanostructured materials for electrochemical energy 
conversion and storage devices. Adv. Mater. 20, 2878-2887 (2008).

2. Peng, S. et al., Fabrication of spinel one-dimensional architectures by single-spinneret electrospinning for energy storage applications. ACS Nano 9, 1945-1954 (2015).

3. Zhou, Z.-Y.; Tian, N.; Li, J.-T.; Broadwell, I.; Sun, S.-G., Nanomaterials of high surface energy with exceptional properties in catalysis and energy storage. Chem. Soc. Rev. 40, 4167-4185 (2011).

4. Wang, Z. L., Nanowires and nanobelts: materials, properties and devices. Volume 1: Metal and Semiconductor Nanowires. (Springer Science \& Business Media: 2013).

5. Xia, Y. et al. One-dimensional nanostructures: synthesis, characterization, and applications. Adv. Mater. 15, 353-389 (2003).

6. Sun, Z. et al. Generalized self-assembly of scalable two-dimensional transition metal oxide nanosheets. Nat. Commun. 5, 3813 (2014).

7. Jana, N. R.; Gearheart, L.; Murphy, C. J., Seed-mediated growth approach for shapecontrolled synthesis of spheroidal and rod-like gold nanoparticles using a surfactant template. Adv. Mater. 13, 1389 (2001).

8. Huczko, A., Template-based synthesis of nanomaterials. Appl. Phys. A 70, 365-376 (2000).

9. Tao, A. R.; Habas, S.; Yang, P., Shape control of colloidal metal nanocrystals. Small 4, 310325 (2008).

10. Li, Y. et al. Electrochemically shape-controlled synthesis of trapezohedral platinum nanocrystals with high electrocatalytic activity. Chem. Commun. 48, 9531-9533 (2012).

11. Lifshitz, I. M.; Slyozov, V. V., The kinetics of precipitation from supersaturated solid solutions. J. Phys. Chem. Solids 19, 35-50 (1961).

12. Li, W.; Zhang, S.; Chen, J., Synthesis, characterization, and electrochemical application of $\mathrm{Ca}(\mathrm{OH})_{2}-, \mathrm{Co}(\mathrm{OH})_{2}-$, and $\mathrm{Y}(\mathrm{OH})_{3}-\mathrm{coated} \mathrm{Ni}(\mathrm{OH})_{2}$ tubes. J. Phys. Chem. $B$ 109, 1402514032 (2005).

13. Lin, H.-X et al. Supersaturation-dependent surface structure evolution: From ionic, molecular to metallic micro/nanocrystals. J. Am. Chem. Soc. 135, 9311-9314 (2013).

14. Mullin JW. Crystallization. (Butterworth-Heinemann, 2001).

15. Söhnel, O. \& Garside, J. Precipitation: basic principles and industrial applications. (Butterworth-Heinemann, 1992).

16. Peng, X., Mechanisms for the shape control and shape evolution of colloidal semiconductor 
nanocrystals. Adv. Mater. 15, 459-463 (2003).

17. Myerson, A. S.; Trout, B. L., Nucleation from solution. Science 341,855-856 (2013).

18. Gebauer, D.; Völkel, A.; Cölfen, H., Stable prenucleation calcium carbonate clusters. Science 322, 1819-1822 (2008).

19. Kaplan, C. N. et al. Controlled growth and form of precipitating microsculptures. Science 355 , 1395-1399 (2017).

20. Lee, S. M.; Cho, S. N.; Cheon, J., Anisotropic shape control of colloidal inorganic nano-crystals. Adv. Mater. 15, 441-444 (2003).

21. Pauling, L., General Chemistry. (Courier Corporation: 1988).

22. Zhang, X.; Xie, Y., Recent advances in free-standing two-dimensional crystals with atomic thickness: design, assembly and transfer strategies. Chem. Soc. Rev. 42, 8187-8199 (2013).

23. Guan, H. et al. CoO octahedral nanocages for high-performance lithium ion batteries. Chem. Commun. 48, 4878-4880 (2012).

24. Jiang, J. et al. Direct synthesis of $\mathrm{CoO}$ porous nanowire arrays on $\mathrm{Ti}$ substrate and their application as lithium-ion battery electrodes. J. Phys. Chem. C 114, 929-932 (2009).

25. Yao, W., Yang, J., Wang, J. \& Nuli, Y. Multilayered cobalt oxide platelets for negative electrode material of a lithium-ion battery. J. Electrochem. Soc. 155, A903-A908 (2008).

26. Qiao, H. et al. One-pot synthesis of $\mathrm{CoO} / \mathrm{C}$ hybrid microspheres as anode materials for lithiumion batteries. J. Power Sources 185, 486-491 (2008).

27. Wu, F. D. \& Wang, Y. Self-assembled echinus-like nanostructures of mesoporous $\mathrm{CoO}$ nanorod@ CNT for lithium-ion batteries.J. Mater.Chem. 21, 6636-6641 (2011).

28. Sun, Y., Hu, X., Luo, W. \& Huang, Y. Self-assembled mesoporous CoO nanodisks as a longlife anode material for lithium-ion batteries. J. Mater. Chem. 22, 13826-13831 (2012).

29. Liu, J. et al. Self-assembled porous hierarchical-like CoO@ C microsheets transformed from inorganic-organic precursors and their lithium-ion battery application. CrystEngComm 14, 26692674 (2012).

30. Cao, K. et al. Ultra - High Capacity Lithium - Ion Batteries with Hierarchical CoO Nanowire Clusters as Binder Free Electrodes. Adv. Func. Mater. 25, 1082-1089 (2015).

\section{Data availability statement}


All data supporting the findings of this study are included in the Article and its Supplementary Information, and are also available from the authors upon reasonable request.

\section{Acknowledgments}

This work is financially supported by the Australian Research Council (ARC) (LP120200432, DE170100928 and DP140104062), the National Natural Science Foundation of China (Nos. 21835004, 41430644 and 21671131), MOST (2017YFA0206700 and 2016YFA0202500) and the Program for Changjiang Scholars and Innovation Research Team in University (No. IRT-17R71). We thank the UOW Electron Microscopy Centre for use of the facilities (LE0882813 and LE0237478). We also thank Dr. Tania Silver for critical reading of the manuscript and master's student Yanfei Xu for her partial support in the synthesis of these materials.

\section{Author information}

\section{Affiliations}

Institute for Superconducting \& Electronic Materials, Innovation Campus, University of Wollongong, Wollongong, NSW 2500, Australia

Wei-Hong Lai, Yun-Xiao Wang, Jia-Zhao Wang, Hua-Kun Liu, Shu-Lei Chou, Shi-Xue Dou.

Shanghai Applied Radiation Institute, Faculty of Environmental and Chemical Engineering, Shanghai University, 99 Shangda Road, Shanghai 200444

Yong Wang, Minghong Wu

Key Laboratory of Advanced Energy Materials Chemistry (Ministry of Education), College of Chemistry, Nankai University, Tianjin 300071, P. R. China

Jun Chen

\section{Author Contributions}

W.H. L. and Y.X.W. contributed equally to this work. W.H.L., Y.X.W., S.L.C., and S.X.D conceived and designed the study. W.H.L. performed the synthetic experiments. W.H.L., Y.X.W., Y.W., S.L.C., J.Z.W., M.H.W., and J.C. analyzed data for all compounds. Y.X.W. performed the initial experiments and tested the battery performance of certain materials. W.H.L., Y.X.W., Y.W., S.L.C., M.H.W., J.Z.W., J.C., S.X.D, and H.K.L. co-wrote the paper.

\section{Competing interests}

The authors declare no competing interests.

\section{Corresponding authors}

Correspondence to Shu-Lei Chou, Jia-Zhao Wang, Minghong Wu, or Jun Chen

\section{Supplementary information}

Materials and Methods, Supplementary Figures 1-34, and Supplementary Tables 1-4 are available in the online version of the paper. Reprints and permissions information is available online at www.nature.com/reprints. 


\section{Figure captions}

Fig. 1: Morphological evolution of typical materials with 3D, 1D, and 2D nanostructures. af, Typical scanning electron microscope (SEM) (a-fI) and typical transmission electron microscope (TEM) images (a-fII, a-fIII) of several materials in various morphologies; $\mathrm{BaF}_{2}$ (a) $\mathrm{BaMoO}_{4}$ (b) $\mathrm{Mg}(\mathrm{OH})_{2}$ (c) $\mathrm{Co}(\mathrm{OH})_{2}$ (d) $\mathrm{MnOOH}$ (e) $\mathrm{Cu}(\mathrm{OH})_{2}$ (f,i) and $\mathrm{Cu}_{2}(\mathrm{OH})_{2} \mathrm{SO}_{4}$ (f,ii,iii). In each case, panel (i), (ii), (iii)_show 1D, 2D and 3D morphologies, respectively, and (iv) shows the $\alpha$ and $S$ conditions that promoted the growth of these structures.

Fig. 2: TEM and SEM images of various materials produced by the versatile precipitation. a-d, TEM images of $1 \mathrm{D}$ materials, including $\mathrm{BaCO}_{3}$ nanoneedles (a), $\mathrm{CoCO}_{3}$ nanoneedles (b), $\mathrm{Zn}(\mathrm{OH})_{2}$ nanorods (c), and $\mathrm{CoC}_{2} \mathrm{O}_{4}$ nanorods (d). e-h, TEM images of various 2D materials, including nanosheet-like $\mathrm{Ni}(\mathrm{OH})_{2}(\mathrm{e}), \mathrm{CoSOH}(\mathrm{f}), \mathrm{Ca}_{3}\left(\mathrm{PO}_{4}\right)_{2}$ (g), and $\mathrm{CoCO}_{3}(\mathrm{~h})$. i-l SEM images of diverse 3D polyhedral materials, including $\mathrm{Ca}(\mathrm{OH})_{2}(\mathrm{i}), \mathrm{CaCO}_{3}(\mathrm{j}), \mathrm{CuC}_{2} \mathrm{O}_{4}(\mathrm{k})$, and $\mathrm{Ca}\left(\mathrm{IO}_{3}\right)_{2}$ (1).

Fig. 3: Summary of the synergy between $\alpha$ and $S$ for materials with different morphologies. a, Dispersion of $\mathrm{K}_{\mathrm{sp}}$ of various materials depending on $\alpha$ and $S$ (Note: the small coloured dots represent the projection of the data points on each corresponding $2 \mathrm{D}$ graphs in $\mathrm{b}$ and $\mathrm{c}$ ). b, Projected image of $S$ and $\mathrm{K}_{\mathrm{sp}}$ of $1 \mathrm{D}$ and 2D materials; the regions shaded in pink and blue highlight the 2D structure and 1D structures, respectively. c, Projected image of $\alpha$ and $K_{\mathrm{sp}}$ : both of the 1D and 2D materials are anisotropic materials, while the 3D structures are considered isotropic; they are highlighted by brown and dark-blue shading, respectively. d, The average values of $S\left(S_{a}\right)$ of 3D polyhedra (green bar), spheres (blue bar), and irregular particles (cyan bar). Data represents the means value; Error bars represent standard deviation, $n=3$ independent experiments.

Fig. 4: The mechanism of the formation of 1D, 2D, and 3D morphologies. a, Schematic illustrations of the formation of 1D, 2D, and 3D structures with regular shapes. Color code: Green arrow: 1D reacting path; Orange arrow: 2D reacting path; Blue arrow: 3D reacting path; Purple arrow: the value of $\alpha$; Red arrow: the value of $S$. b-e, TEM images of a $\mathrm{BaF}_{2}$ tube (b), a hollow $\mathrm{BaF}_{2}$ cube (c), a porous $\mathrm{CaF}_{2}$ cube (d), and a holey $\mathrm{Co}(\mathrm{OH})_{2}$ sheet (e). 